Jurnal Mahasiswa BK An-Nur :Berbeda, Bermakna, Mulia

Volume 7 Nomor 3 Tahun 2021

Tersedia Online: https://ojs.uniska-bjm.ac.id/index.php/AN-NUR

p-ISSN. 2460-9722 | e-ISSN. 2622-8297

\title{
PENERAPAN OPEN CLASS DALAM LAYANAN BIMBINGAN KELOMPOK SEBAGAI SARANA MENINGKATKAN KETERAMPILAN KONSELING GURU BK DI SMK
}

\author{
Ratih Christiana ${ }^{1}$, Gatot Noor Effendi ${ }^{2}$, Yustina Kristiani ${ }^{3}$, Eni Andayani ${ }^{4}$, Komisah $^{5}$, Hasma \\ Nurhayati ${ }^{6}$ \\ ${ }^{1}$ Universitas PGRI Madiun (Bimbingan dan Konseling, Fakultas Keguruan dan Ilmu Pendidikan) \\ $2,3,4,5,6$ SMK Negeri 5 Madiun \\ E-mail: ratihchristiana@unipma.ac.id/ 0852-3504-6755
}

\begin{abstract}
ABSTRAK (10 pt)
Abstrak Artikel ini bertujuan untuk meningkatkan kualitas keterampilan konseling pada layanan bimbingan kelompok Guru BK di SMK dengan menerapkan open class. Responden penelitian ini terdiri dari 4 Guru Bimbingan dan Konseling yang bekerja di SMK yang memiliki kualfikasi masa kerja minimal 4 tahun, berpendidikan minimal S1, bersedia melakukan rangkaian kegiatan lesson study dan bersedia menjadi guru model pada open class layanan bimbingan kelompok. Instrumen penelitian berupa hasil evaluasi dan refleksi konseli, hasil wawancara, hasil dokumentasi, hasil observasi dari peneliti, kolega bimbingan dan konseling, dan catatan penelitian. Metode penelitian menggunakan PTBK dengan rancangan jenis eksperimen model Kurt Lewin, pengujian analisis data berupa reduksi data, penyajian data dan verifikasi data. Hasil penelitian adalah dari aspek keterampilan konseling yang diteliti salah satunya adalah mind skill mampu diterapkan oleh seluruh Guru BK, namun terdapat 2 guru BK yang perlu melatih kembali aspek action skill dan 1 lagi guru BK memerlukan latihan pada communication skill.
\end{abstract}

Kata Kunci: Open Class Layanan Bimbingan Kelompok; Keterampilan Konseling.

\begin{abstract}
$\operatorname{ABSTRACT}(10 \mathrm{pt})$
This article aims to improve the quality of counseling skills in group guidance services for BK teachers in SMK by implementing open classes. Respondents of this study consisted of 4 Guidance and Counseling Teachers who work in Vocational Schools who have a minimum qualification of 4 years of service, have a minimum education of S1, are willing to carry out a series of lesson study activities and are willing to become model teachers in open class group guidance services. The research instruments are the results of the counselee's evaluation and reflection, the results of interviews, the results of documentation, the results of observations from researchers, guidance and counseling colleagues, and research notes. The research method uses PTBK with the experimental type design of the Kurt Lewin model, testing data analysis in the form of data reduction, data presentation and data verification. The results of the research are from the aspect of counseling skills studied, one of which is mind skills that can be applied by all BK teachers, but there are 2 BK teachers who need to retrain aspects of action skills and 1 more BK teachers need training in communication skills.
\end{abstract}

Keywords: Open Class in Group Guidance Service; Skill Counseling.

DipublikasikanOleh :

UPT PublikasidanPengelolaanJurnal

Universitas Islam Kalimantan Muhammad Arsyad Al-Banjari Banjarmasin 


\section{PENDAHULUAN}

Peningkatan kualitas pendidikan dan mutu layanan konseling yang baik diharapkan mampu melahirkan Guru Bimbingan dan Konseling (Guru BK) yang mempunyai daya saing tinggi untuk menghadapi ketatnya tantangan dan persaingan di dunia kerja (Christiana \& Krisphianty, 2020). Perlu dilakukan perbaikan yang membangun di bidang pendidikan, khususnya bidang bimbingan dan konseling dengan terus melaksanakan latihan keterampilan konseling guna mencapai kualitas dan mutu pendidikan yang sesuai dengan harapan yang di butuhkan konseli (Suharni \& Christiana, 2020).

Upaya perbaikan mutu pendidikan menjadi tanggung jawab semua pihak, salah satunya adalah Konselor dan Guru BK. Sebagaimana dijelaskan oleh Mullen et al. (2015) yang menyatakan bahwa konselor bertanggung jawab melaksanakan layanan konseling, baik di sekolah maupun di luar sekolah dalam arti memberikan bimbingan dan pelayanan profesional kepada tiap individu sesuai kebutuhan. konselor harus dapat melakukan inovasi yang menyangkut tugasnya sebagai pendidik yang berkaitan dengan tugas mendampingi siswa agar mampu mengeksplorasi potensinya (Burck et al, 2014).

Inovasi-inovasi yang di lakukan oleh konselor sebagai pendidik diharapkan bukan hanya mampu meningkatkan prestasi belajar peserta didik dengan menyelaraskan need assesment, namun juga mewujudkan kebahagiaan belajar peserta didik sebagaimana esensi dari konsep merdeka belajar (Nita et al 2020). Mengingat bahwa konselor memberi pengaruh terhadap rencana karir dan prestasi belajar peserta didik. Sebagaimana dikemukakan oleh Suryadi et al (2020) bahwa peran seorang konselor sangat berpengaruh terhadap hasil belajar dan orientasi karir yang dapat dicapai oleh peserta didiknya. Oleh karena itu, inovasi pendidikan berkaitan dengan tugas layanan konseling penting untuk ditingkatkan.

Konselor dalam melaksanakan tugas layanan konseling terkadang terdapat hambatan, baik hambatan sebelum pelaksaan ataupun saat pelaksanaannya. Begitu pula dalam melaksanakan tugas profesional, di ungkapkan oleh Menendez et al. (2020), konselor juga mempunyai hambatan dari berbagai aspek, baik hambatan sederhana bahkan sampai hambatan yang serius. Seorang konselor pada saat melakukan layanan konseling juga tak menutup kemungkinan memiliki keterbatasan dalam aspek afektif, kognitif dan terkadang berpengaruh terhadap perilaku, sehingga terkadang proses bantuan terhadap konseli menjadi tidak efektif (Gask, L \& Graham, 2014).

Layanan konseling terutama bimbingan kelompok yang kurang efektif tersebut dapat di minimalisir, sehingga bimbingan kelompok dapat berjalan dengan lancar serta gayut dengan kebutuhan konseli, baik pada saat praktek maupun realisasinya. Perlu dilakukan penerapan strategi pembelajaran yang dapat memberikan pengalaman belajar secara langsung melalui penggunaan dan pengembangan ketrampilan konseling, baik itu proses dan sikap ilmiah dengan tujuan untuk memahami konsep materi dan mampu memecahkan masalah dalam pelaksanaan konseling (Mappiare, Ramli, and Radjah, 2020).

Di Indonesia telah berjalan, dikembangkan dan di implementasikan upaya peningkatan profesionalisme pendidik melalui kegiatan yang disebut lesson study. Lesson study ditujukan untuk meningkatkan pembelajaran dan kompetensi pendidik melalui pengkajian pembelajaran secara kolaboratif dan berkelanjutan (Susilo, 2013). Lesson study bukan merupakan metode pembelajaran maupun pendekatan pembelajaran (Dudley, 2015), namun Lesson study adalah model pembinaan profesi pendidik melalui pengkajian pembelajaran secara kolaboratif dan berkelanjutan berlandaskan prinsip kolegalitas yang saling membantu dalam belajar untuk membangun komunitas belajar (Flecknoe, 1999; Saito \& Sato, 2012).

Model pembinaan profesi pendidik juga penting di berikan kepada konselor dan Guru BK dalam meningkatkan keterampilan konseling pada saat memberikan layanan konseling berupa bimbingan kelompok. Selain di bekali teori dan praktik konseling, konselor dan Guru BK juga dirasa perlu di fasilitasi dengan lesson study. Bimbingan kelompok merupakan layanan yang memberikan informasi kepada sekelompok siswa dalam rangka mendampingi siswa merencanakan tujuan dan keputusan yang tepat, maka dari itu perlu pengamatan yang intens dalam proses layanan bimbingan kelompok agar mampu mewujudkan tujuan siswa dalam merencanakan pengambilan keputusan yang sesuai dengan kebutuhan.

Pengamatan atau observasi layanan bimbingan kelompok tersebut dapat dilaksanakan dengan kegiatan membuka kelas atau biasa disebut dengan open class dalam istilah lesson study. open class bimbingan kelompok ini bermanfaat untuk memperbaiki kualitas keterampilan konseling dalam

DipublikasikanOleh : 
rangka pemberian layanan konseling dalam sebuah kelompok. Selain itu observer juga mengetahui apa yang dilakukan siswa pada saat proses kegiatan layanan bimbingan kelompok berlangsung, karena yang paling utama adalah kenyamanan siswa dalam kelompoknya agar muncul dinamika kelompok yang tercermin dalam sikap lebih mengenal dirinya sendiri dan orang lain, sikap saling membutuhkan, saling melengkapi satu sama lain dan mampu bekerja sama dengan anggota kelompoknya.

\section{Open Class Layanan Bimbingan Kelompok} 1.1 Pengertian Open Class dalam Layanan Bimbingan Kelompok

Open Class adalah tahapan proses pelaksanaan pada hasil rencana yang telah dirancang sedemikian rupa sesuai dengan kebutuhan siswa pada tahap plan atau rencana (Ahmad 2019), yang terdapat peraturan dalam kegiatan open class. Peraturan open class ini disusun berdasarkan tiga sesi, yakni sebelum pengamatan, selama pengamatan, dan setelah pengamatan.

Sebelum pengamatan, siswa diminta datang ke sekolah 15 menit sebelum layanan bimbingan kelompok dimulai untuk memulai mengikuti kegiatan informatif yang dipaparkan guru BK model terhadap tema layanan sesuai dengan Rencana Pelaksanaan Layanan Bimbingan dan Konseling (RPLBK) merupakan sebuah perangkat pembelajaran BK yang di susun dalam rencana layanan bimbingan kelompok (Plan) sebagai acuan dalam pelaksanaan layanan BK (Do). Kemudian observer menyiapkan buku catatan dan alat perekam (apabila diperlukan) untuk kebutuhan dokumentasi.

Selama Pengamatan, seluruh observer memasuki ruangan dan mengambil tempat sesuai dengan kenyamanan dan kebutuhan observasi pada proses bimbingan kelompok, sebelum layanan dimulai dengan catatan, bahwa observer adalah "angin" yang berada di sekitar kegiatan layanan bimbingan kelompok dan tidak mengganggu aktivitas layanan bimbingan kelompok. Para observer mengamati secara detail dari menit ke menit proses layanan bimbingan kelompok, fokus pengamatan observer terpusat pada perilaku siswa dalam mengikuti layanan konseling. Hampir tiap kejadian terekam dalam catatan lembar observasi dan apabila dibutuhkan observer mendokumentasikan melalui video, foto dan alat perekam.
Seteleh Pengamatan, pasca aktivitas observasi terhadap proses layanan bimbingan kelompok di ruangan selesai, seluruh observer memasuki ruangan yang telah disediakan dengan dipandu oleh mederator untuk mengadakan tahapan refleksi. Refleksi tersebut menggunakan instrumen sejumlah 4 pertanyaan terbuka untuk mengetahui kondisi guru model pada saat melakukan proses open class layanan bimbingan kelompok.

\subsection{Langkah-langkah Open Class Layanan Bimbingan Kelompok}

Langkah-langkah dalam melaksanakan open class bimbingan kelompok antara lain: (1) Tahap Pembentukan, (2) Tahap Peralihan, (3) Tahap Kegiatan, (4) Tahap Pengakhiran. Bimbingan kelompok yang akan di fasilitasi dengan open class lesson study fokus kepada kegiatan (1) Perencanaan layanan bimbingan kelompok (Plan), (2) Pelaksanaan bimbingan kelompok (Do), (3) Mengamati proses layanan bimbingan kelompok oleh observer (See), (4) Mengacu pada pelaksanaan kegiatan (Refleksi) (5) Tindak lanjut dari layanan bimbingan kelompok (Follow up).

\section{Keterampilan Konseling}

Menurut Jones (2014) maksud dan tujuan keterampilan konseling adalah untuk membantu konseli mengembangkan keterampilan pribadi dan Inner strength (kekuatan batin), agar dapat menciptakan kebahagiaan dalam kehidupannya sendiri dan orang lain. keterampilan konseling dapat dibagi menjadi lima tujuan yang berbeda sesuai dengan situasi.

Lima tujuan keterampilan konseling menurut Jones (2005) diantaranya adalah (a) Tujuan Supportive Listening adalah untuk memberi konseli perasaan dipahami dan di afirmasi, pencapaiannya mengharuskan konselor mendengarkan persektif dan secara sensitif menunjukkan bahwa konseli telah di dengarkan secara akurat, (b) Mengelola Situasi Bermasalah dengan mencoba menangani situasi tertentu di dalam masalah, bukan menangani seluruh masalahnya, (c) Problem management yaitu bersama-sama antara konseli dan konselor mengidentifikasi dimensi permasalahan serta turut serta dalam mengatur kenyataan hidup yang membuat selama ini 'lari' dari permasalahan, (d) Mengubah Keterampilan Buruk yang Menciptakan Masalah, keterampilan buruk (keterampilan

DipublikasikanOleh :

UPT PublikasidanPengelolaanJurnal

Universitas Islam Kalimantan Muhammad Arsyad Al-Banjari Banjarmasin 
Ratih Christiana ${ }^{1}$, Gatot Noor Effendi ${ }^{2}$, Yustina Kristiani ${ }^{3}$,

Eni Andayani ${ }^{4}$, Komisah $^{5}$, Hasma Nurhayati ${ }^{6}$

Jurnal Mahasiswa BK An-Nur :Berbeda, Bermakna, Mulia

Volume 7 Nomor 3 Tahun 2021

Tersedia Online: https://ojs.uniska-bjm.ac.id/index.php/AN-NUR

p-ISSN. 2460-9722 | e-ISSN. 2622-8297

problematik, defisien atau tidak efektif), definisi khususnya bahwa masalah cenderung mengulangi diri (defisiensi mind skill atau keterampilan pikiran, communication skills atau keterampilan komunikasi, action skills atau keterampilan bertindak) dan beresiko mengulang kembali, (e) Mewujudkan Falsafah Hidup dengan mengelola problem situations menjadi problematic skills.

\section{METODE}

Penelitian ini menggunakan Penelitian Tindakan Bimbingan dan Konseling (PTBK) dengan rancangan jenis eksperimental model penelitian tindakan Kurt Lewin, yang tervisualisasi pada gambar 1. Data didapatkan dengan menggunakan (1) Hasil evaluasi dan refleksi konseli dalam menyelesaikan lembar kerja yang di berikan, (2) Hasil wawancara antara peneliti dengan Guru BK yang dijadikan subyek penelitian, (3) Hasil dokumentasi yang diperoleh dari pengamatan peneliti selama bimbingan kelompok berlangsung, (4) Hasil observasi yang diperoleh dari pengamatan rekan sejawat dan Guru BK dari SMK lain, (5) Catatan lapangan dari rangkaian kegiatan siswa sebagai konseli dalam layanan konseling selama penelitian. Subyek penelitian adalah Guru Bimbingan dan Konseling di SMK di Kota Madiun yang memiliki kualifikasi masa kerja minimal 4 tahun, minimal berpendidikan S1, Guru BK bersedia melakukan rangkaian kegiatan lesson study dan bersedia menjadi guru model pada pelaksanaan open class bimbingan kelompok. Analisis data pada pengujian instrument menggunakan reduksi data, penyajian data dan penarikan kesimpulan atau verifikasi data.

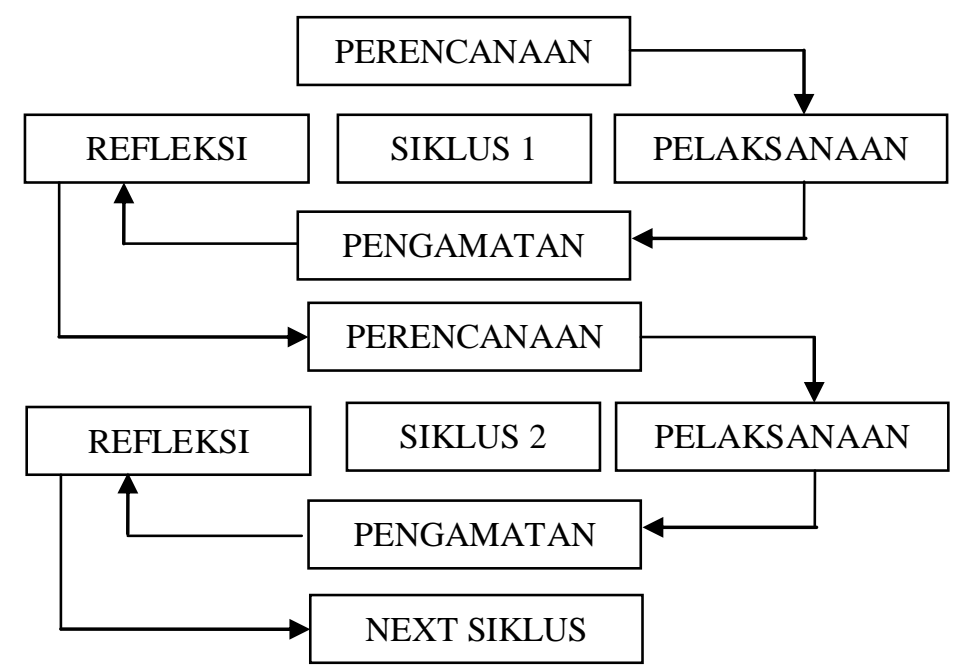

Gambar 1. PTBK Rancangan Eksperimental Model Kurt Lewin

\section{HASIL DAN PEMBAHASAN}

Penelitian dilakukan sebanyak empat siklus dimulai sejak tanggal 2 Agustus - 10 November 2021, yang masing-masing siklus diberikan jeda dua minggu hingga tiga minggu. Berdasarkan data yang telah diamati peneliti selama proses lesson study, mulai dari Plan, Do dan See dapat di ketahui bahwa kewajiban Guru BK dalam memberikan layanan konseling terutama bimbingan kelompok, wajib menggunakan keterampilan konseling.

Pada penelitian tindakan BK ini menggunakan satu tujuan dari lima keterampilan konseling, yakni mengubah keterampilan buruk yang menciptakan masalah, berisi tiga aspek yang gayut apabila digunakan dalam layanan bimbingan kelompok. Tiga aspek tersebut adalah (1) Mind Skill atau keterampilan pikiran, (2) Communication skills atau keterampilan komunikasi, (3) Action skills atau keterampilan bertindak. Selain itu peneliti juga mengamati persiapan dalam menyusun perangkat layanan atau biasa disebut RPLBK (Rancangan Pelaksanaan Layanan Bimbingan dan Konseling) untuk setiap kali pertemuan. RPLBK ini nantinya akan digunakan pada saat pelaksanaan open class bimbingan kelompok yang disusun berdasarkan kondisi observasi di awal

\section{DipublikasikanOleh :}


Ratih Christiana ${ }^{1}$, Gatot Noor Effendi ${ }^{2}$, Yustina Kristiani ${ }^{3}$,

Eni Andayani ${ }^{4}$, Komisah $^{5}$, Hasma Nurhayati ${ }^{6}$

Jurnal Mahasiswa BK An-Nur :Berbeda, Bermakna, Mulia

Volume 7 Nomor 3 Tahun 2021

Tersedia Online: https://ojs.uniska-bjm.ac.id/index.php/AN-NUR

p-ISSN. 2460-9722 | e-ISSN. 2622-8297

sebelum diskusi mengenai general plan (rencana secara umum).

Bagian ini diuraikan tentang ketercapaian hasil penelitian yang telah dilakukan selama kurang lebih 3 bulan yang nantinya hasil akan di implementasikan kepada mahasiswa calon konselor di Universitas, maka hasil dari siklus 1, 2, 3 dan 4 penelitian tindakan bimbingan dan konseling dapat divisualisasikan pada tabel 1, tabel 2, tabel 3 dan tabel 4.

\section{Siklus 1}

Tabel 1. Rekapitulasi Data Penelitian pada Siklus 1 (Tanggal 19 Agustus 2021)

\begin{tabular}{|c|c|c|c|c|}
\hline $\begin{array}{l}\text { Guru } \\
\text { Model }\end{array}$ & $\begin{array}{l}\text { Tema Bimbingan } \\
\text { Kelompok }\end{array}$ & $\begin{array}{c}\text { Indikator } \\
\text { Ketercapaian }\end{array}$ & Capaian & Keterangan \\
\hline \multirow[t]{3}{*}{ GM 1} & $\begin{array}{l}\text { Dengan bimbingan } \\
\text { kelompok } \\
\text { kemampuan belajar }\end{array}$ & Mind Skill & $\begin{array}{l}\text { Belum memahami peralihan } \\
\text { layanan bimbingan kelompok } \\
\text { dengan baik }\end{array}$ & Tidak tercapai \\
\hline & $\begin{array}{l}\text { siswa menjadi } \\
\text { meningkat }\end{array}$ & Communication skills & $\begin{array}{l}\text { Menyampaikan tema dengan } \\
\text { lugas kepada konseli }\end{array}$ & Tercapai \\
\hline & & Action skills & $\begin{array}{l}\text { Ice breaking kurang } \\
\text { menghidupkan dinamika } \\
\text { kelompok }\end{array}$ & Kurang Tercapai \\
\hline \multirow[t]{3}{*}{ GM 2} & $\begin{array}{l}\text { Kepedulian terhadap } \\
\text { diri sendiri dan }\end{array}$ & Mind Skill & $\begin{array}{l}\text { Belum menguasai tema } \\
\text { bimbingan kelompok }\end{array}$ & Tidak Tercapai \\
\hline & lingkungan sosial & Communication skills & $\begin{array}{l}\text { Pemilihan kalimat perlu di } \\
\text { asah kembali }\end{array}$ & Kurang Tercapai \\
\hline & & Action skills & $\begin{array}{l}\text { Belum menguasai karakter } \\
\text { kelompok }\end{array}$ & Kurang Tercapai \\
\hline \multirow[t]{3}{*}{ GM 3} & $\begin{array}{l}\text { Menumbuhkan jiwa } \\
\text { kewirausahaan }\end{array}$ & Mind Skill & $\begin{array}{l}\text { Pemberian contoh kasus } \\
\text { kurang dapat dipahami siswa }\end{array}$ & Tidak Tercapai \\
\hline & & Communication skills & Terlalu banyak unsur instruksi & Kurang Tercapai \\
\hline & & Action skills & $\begin{array}{l}\text { Belum menguasai karakter } \\
\text { kelompok }\end{array}$ & Kurang Tercapai \\
\hline \multirow[t]{3}{*}{ GM 4} & $\begin{array}{l}\text { Chritical Thinking } \\
\text { (Berpikir kritis) }\end{array}$ & Mind Skill & $\begin{array}{l}\text { Sebagian besar RPLBK tidak } \\
\text { tersampaikan }\end{array}$ & Kurang Tercapai \\
\hline & & Communication skills & Terlalu mendominasi & Kurang Tercapai \\
\hline & & Action skills & Antusiasme siswa terlihat & Tercapai \\
\hline
\end{tabular}

Siklus 2

Tabel 2. Rekapitulasi Data Penelitian pada Siklus 2 (Tanggal 7 September 2021)

\begin{tabular}{|c|c|c|c|c|}
\hline $\begin{array}{l}\text { Guru } \\
\text { Model }\end{array}$ & $\begin{array}{c}\text { Tema Bimbingan } \\
\text { Kelompok }\end{array}$ & $\begin{array}{c}\text { Indikator } \\
\text { Ketercapaian }\end{array}$ & Capaian & Keterangan \\
\hline \multirow[t]{3}{*}{ GM 1} & $\begin{array}{l}\text { Dengan bimbingan } \\
\text { kelompok } \\
\text { kemampuan belajar }\end{array}$ & Mind Skill & $\begin{array}{l}\text { Memberikan contoh tidak } \\
\text { sesuai dengan tugas } \\
\text { perkembangan siswa SMK }\end{array}$ & Kurang tercapai \\
\hline & $\begin{array}{l}\text { siswa menjadi } \\
\text { meningkat }\end{array}$ & Communication skills & $\begin{array}{l}\text { Menyampaikan materi dengan } \\
\text { lugas kepada konseli }\end{array}$ & Tercapai \\
\hline & & Action skills & $\begin{array}{l}\text { Belum mampu mewujudkan } \\
\text { dinamika kelompok }\end{array}$ & Kurang tercapai \\
\hline GM 2 & $\begin{array}{l}\text { Kepedulian terhadap } \\
\text { diri sendiri dan } \\
\text { lingkungan sosial }\end{array}$ & Mind Skill & $\begin{array}{l}\text { Spontanitas ide yang } \\
\text { diberikan untuk menginspirasi } \\
\text { siswa }\end{array}$ & Tercapai \\
\hline
\end{tabular}

DipublikasikanOleh :

UPT PublikasidanPengelolaanJurnal

Universitas Islam Kalimantan Muhammad Arsyad Al-Banjari Banjarmasin 
Ratih Christiana ${ }^{1}$, Gatot Noor Effendi ${ }^{2}$, Yustina Kristiani ${ }^{3}$,

Eni Andayani ${ }^{4}$, Komisah $^{5}$, Hasma Nurhayati ${ }^{6}$

Jurnal Mahasiswa BK An-Nur :Berbeda, Bermakna, Mulia

Volume 7 Nomor 3 Tahun 2021

Tersedia Online: https://ojs.uniska-bjm.ac.id/index.php/AN-NUR

p-ISSN. 2460-9722 | e-ISSN. 2622-8297

Communication skills
Action skills
Mind Skill
Communication skills
Action skills

Mind Skill

GM 4 Chritical Thinking (Berpikir kritis)
Kalimat yang di sampaikan kurang terstruktur

Belum mampu mewujudkan dinamika kelompok Ice breaking dan spontanitas dapat diikuti oleh siswa Unsur instruksi masih ada Belum mampu mewujudkan dinamika kelompok kelompok Sesuai dengan RPLBK dan mampu merespon kondisi anggota kelompok dengan baik

Communication skills Pemberian stimulus berupa komunikasi belum mampu membuat siswa menjawab

Action skills
Kurang tercapai

Kurang tercapai

Tercapai

Kurang tercapai

Kurang tercapai

Tercapai

Kurang Tercapai

Tercapai terbangun

\section{Siklus 3}

Tabel 3. Rekapitulasi Data Penelitian pada Siklus 3 (Tanggal 28 September 2021)

\begin{tabular}{|c|c|c|c|c|}
\hline $\begin{array}{l}\text { Guru } \\
\text { Model }\end{array}$ & $\begin{array}{c}\text { Tema Bimbingan } \\
\text { Kelompok }\end{array}$ & $\begin{array}{c}\text { Indikator } \\
\text { Ketercapaian }\end{array}$ & Capaian & Keterangan \\
\hline \multirow[t]{3}{*}{ GM 1} & $\begin{array}{l}\text { Motivasi Belajar di } \\
\text { tinjau dr Bakat dan } \\
\text { Minat }\end{array}$ & Mind Skill & $\begin{array}{l}\text { Belum memahami tema } \\
\text { layanan bimbingan kelompok } \\
\text { dengan baik }\end{array}$ & Tidak tercapai \\
\hline & & Communication skills & Banyak pengulangan kalimat & Kurang tercapai \\
\hline & & Action skills & Fokus ke siswa tertentu saja & Tercapai \\
\hline \multirow[t]{3}{*}{ GM 2} & $\begin{array}{l}\text { Kepedulian terhadap } \\
\text { diri sendiri }\end{array}$ & Mind Skill & $\begin{array}{l}\text { Belum menguasai tema } \\
\text { bimbingan kelompok }\end{array}$ & Kurang tercapai \\
\hline & & Communication skills & $\begin{array}{l}\text { Mampu menyampaikan } \\
\text { kalimat secara terstruktur }\end{array}$ & Tercapai \\
\hline & & Action skills & $\begin{array}{l}\text { posisi letter U mengakibatkan } \\
\text { kurang leluasa memberikan } \\
\text { informasi }\end{array}$ & Kurang tercapai \\
\hline \multirow[t]{3}{*}{ GM 3} & $\begin{array}{l}\text { Inisiatif siswa } \\
\text { berangkat dari }\end{array}$ & Mind Skill & $\begin{array}{l}\text { Pemberian contoh kasus } \\
\text { kurang dapat dipahami siswa }\end{array}$ & Kurang tercapai \\
\hline & kesadaran diri & Communication skills & $\begin{array}{l}\text { Perlu menyesuaikan } \\
\text { komunikasi dengan gaya } \\
\text { bahasa siswa SMK }\end{array}$ & Kurang tercapai \\
\hline & & Action skills & $\begin{array}{l}\text { Perlu pendekatan kembali } \\
\text { dengan konseli agar tidak } \\
\text { terjadi hierarki }\end{array}$ & Kurang tercapai \\
\hline \multirow[t]{3}{*}{ GM 4} & Problem Solving & Mind Skill & $\begin{array}{l}\text { Mampu memberikan } \\
\text { gambaran kasus dan } \\
\text { pemecahannya }\end{array}$ & Tercapai \\
\hline & & Communication skills & $\begin{array}{l}\text { Berusaha memberikan ruang } \\
\text { untuk pendapat siswa }\end{array}$ & Tercapai \\
\hline & & Action skills & Kreatif dalam memunculkan & Tercapai \\
\hline
\end{tabular}

DipublikasikanOleh :

UPT PublikasidanPengelolaanJurnal

Universitas Islam Kalimantan Muhammad Arsyad Al-Banjari Banjarmasin 
Ratih Christiana ${ }^{1}$, Gatot Noor Effendi ${ }^{2}$, Yustina Kristiani ${ }^{3}$,

Eni Andayani ${ }^{4}$, Komisah $^{5}$, Hasma Nurhayati ${ }^{6}$

Jurnal Mahasiswa BK An-Nur :Berbeda, Bermakna, Mulia

Volume 7 Nomor 3 Tahun 2021

Tersedia Online: https://ojs.uniska-bjm.ac.id/index.php/AN-NUR

p-ISSN. 2460-9722 | e-ISSN. 2622-8297

dinamika kelompok

Siklus 4

Tabel 4. Rekapitulasi Data Penelitian pada Siklus 4 (Tanggal 14 Oktober 2021)

\begin{tabular}{|c|c|c|c|c|}
\hline $\begin{array}{l}\text { Guru } \\
\text { Model }\end{array}$ & $\begin{array}{c}\text { Tema Bimbingan } \\
\text { Kelompok }\end{array}$ & $\begin{array}{c}\text { Indikator } \\
\text { Ketercapaian }\end{array}$ & Capaian & Keterangan \\
\hline \multirow[t]{3}{*}{ GM 1} & $\begin{array}{l}\text { Motivasi Belajar di } \\
\text { tinjau dr Bakat dan } \\
\text { Minat }\end{array}$ & Mind Skill & $\begin{array}{l}\text { Belum memahami peralihan } \\
\text { layanan bimbingan kelompok } \\
\text { dengan baik }\end{array}$ & Tercapai \\
\hline & & Communication skills & $\begin{array}{l}\text { Ruangan yang luas berpengaruh } \\
\text { terhadap kualitas tinggi } \\
\text { rendahnya suara dan daya } \\
\text { tangkap komunikasi }\end{array}$ & Kurang tercapai \\
\hline & & Action skills & $\begin{array}{l}\text { Memberi perhatian kepada } \\
\text { anggota kelompok yang } \\
\text { memiliki catatan khusus saat } \\
\text { proses layanan bimbingan } \\
\text { kelompok }\end{array}$ & Tercapai \\
\hline \multirow[t]{3}{*}{ GM 2} & $\begin{array}{l}\text { Kepedulian terhadap } \\
\text { diri sendiri }\end{array}$ & Mind Skill & $\begin{array}{l}\text { Mampu menyusun peta } \\
\text { konsep sesuai dengan tema }\end{array}$ & Tercapai \\
\hline & & Communication skills & $\begin{array}{l}\text { Membangun trend komunikasi } \\
\text { dengan gaya bahasa anak muda }\end{array}$ & Tercapai \\
\hline & & Action skills & $\begin{array}{l}\text { Kondisi pasca cidera, namun } \\
\text { siswa antusias mengikuti } \\
\text { layanan bimbingan kelompok }\end{array}$ & Kurang tercapai \\
\hline \multirow[t]{3}{*}{ GM 3} & $\begin{array}{l}\text { Inisiatif siswa } \\
\text { berangkat dari } \\
\text { kesadaran diri }\end{array}$ & Mind Skill & $\begin{array}{l}\text { Responsif ketika menjawab } \\
\text { anggota kelompok, meski } \\
\text { butuh jeda waktu }\end{array}$ & Tercapai \\
\hline & & Communication skills & $\begin{array}{l}\text { Belum mampu membangun } \\
\text { komunikasi dengan anggota } \\
\text { kelompok }\end{array}$ & Kurang tercapai \\
\hline & & Action skills & $\begin{array}{l}\text { Mampu menguasai karakter } \\
\text { kelompok }\end{array}$ & Tercapai \\
\hline \multirow[t]{3}{*}{ GM 4} & Problem Solving & Mind Skill & $\begin{array}{l}\text { Responsif terhadap } \\
\text { permasalahan anggota } \\
\text { kelompok }\end{array}$ & Tercapai \\
\hline & & Communication skills & $\begin{array}{l}\text { Komunikatif agar siswa aktif } \\
\text { dalam diskusi }\end{array}$ & Tercapai \\
\hline & & Action skills & $\begin{array}{l}\text { Kreatif dalam memunculkan } \\
\text { dinamika kelompok }\end{array}$ & Tercapai \\
\hline
\end{tabular}

Hasil penelitian menunjukkan bahwa terjadi peningkatan yang signifikan keterampilan konseling Guru BK di SMK setelah melakukan empat kali siklus layanan bimbingan kelompok dengan menerapkan open class. Terbukti bahwa pada tabel 5 terdapat perbandingan masing-masing siklus antara siklus 1 , siklus 2, siklus 3 dan siklus 4 yang mengalami perubahan.

DipublikasikanOleh :

UPT PublikasidanPengelolaanJurnal

Universitas Islam Kalimantan Muhammad Arsyad Al-Banjari Banjarmasin 
Tabel 5. Perbandingan Masing-Masing Siklus Pada Penerapan Open Class dalam Layanan Bimbingan Kelompok

\begin{tabular}{cl|lll}
\hline Guru Model & \multicolumn{1}{c}{ Siklus 1 } & \multicolumn{1}{c}{ Siklus 2 } & \multicolumn{1}{c}{ Siklus 3 } & \multicolumn{1}{c}{ Siklus 4 } \\
\hline GM 1 & Tidak tercapai & Kurang tercapai & Tidak tercapai & Tercapai \\
& Tercapai & Tercapai & Kurang tercapai & Tercapai \\
& Kurang tercapai & Kurang tercapai & Tercapai & Kurang tercapai \\
GM 2 & Tidak tercapai & Tercapai & Kurang tercapai & Tercapai \\
& Kurang tercapai & Kurang tercapai & Tercapai & Tercapai \\
& Kurang tercapai & Kurang tercapai & Kurang tercapai & Kurang tercapai \\
GM 3 & Tidak tercapai & Tercapai & Kurang tercapai & Tercapai \\
& Kurang tercapai & Kurang tercapai & Kurang tercapai & Kurang tercapai \\
& Kurang tercapai & Kurang tercapai & Kurang tercapai & Tercapai \\
GM 4 & Kurang tercapai & Tercapai & Tercapai & Tercapai \\
& Kurang tercapai & Kurang tercapai & Tercapai & Tercapai \\
& Tercapai & Tercapai & Tercapai & Tercapai
\end{tabular}

Tabel 5 menunjukkan adanya kemajuan pada masing-masing siklus dari siklus 1 sampai dengan siklus 4. Pembahasan tersebut yakni sebagai berikut, GM 1 mengalami naik turun hasil pencapaian pada aspek mind skill, pada siklus 1 mind skill tidak tercapai, siklus 2 mind skill kurang tercapai, siklus 3 mind skill justru tidak tercapai, dan siklus 4 mind skill berhasil dicapai. GM 2 juga demikian mengalami naik turun hasil pencapaian pada aspek mind skill,

pada siklus 1 mind skill tidak tercapai, siklus 2 mind skill tercapai, siklus 3 mind skill kurang tercapai, dan siklus 4 mind skill tercapai. GM 3 pada siklus 1 mind skill tidak tercapai, siklus 2 mind skill tercapai, siklus 3 mind skill kurang tercapai, dan siklus 4 mind skill tercapai. GM 4 pada siklus 1 mind skill kurang tercapai, siklus 2 mind skill tercapai, siklus 3 mind skill tercapai, dan siklus 4 mind skill tercapai. Artinya pada aspek mind skill ini terdapat 3 guru yang perlu beradaptasi kembali dengan tema layanan bimbingan kelompok baru di siklus 3 .

Aspek communication skill GM 1 pada siklus 1 tercapai, siklus 2 communication skill tercapai, siklus 3 communication skill justru mengalami penurunan yakni kurang tercapai, siklus 4 communication skill tercapai. GM 2 pada siklus 1 kurang tercapai, siklus 2 communication skill kurang tercapai, siklus 3 communication skill tercapai, siklus 4 communication skill tercapai. GM 3 mengalami kelemahan pada aspek communication skill di siklus 1 sampai dengan siklus 4, karena hasilnya menunjukkan kurang tercapai. GM 42 pada siklus 1 kurang tercapai, siklus 2 communication skill kurang tercapai, siklus 3 communication skill tercapai, siklus 4 communication skill tercapai.

Aspek action skill GM 1 pada siklus 1 kurang tercapai, siklus 2 action skill tercapai, siklus 3 action skill berhasil tercapai, siklus 4 action skill kurang tercapai. GM 2 pada siklus 1 hingga siklus 4 hasilnya kurang tercapai, hal ini menunjukkan bahwa GM 2 mengalami kelemahan pada aspek action skill. GM 3 pada siklus 1 aspek action skill kurang tercapai, siklus 2 action skill kurang tercapai, siklus 3 action skill kurang tercapai, namun siklus 4 action skill berhasil tercapai. GM 4 pada siklus 1 hingga siklus 4 aspek action skill mengalami keberhasilan, hal ini menunjukkan bahwa GM 4 memiliki kelebihan pada aspek action skill.

\section{PENUTUP}

Bahwa untuk meningkatkan keterampilan konseling pada Guru BK di SMK dalam melakukan layanan bimbingan kelompok yang di implementasikan melalui mind skill, comunication skill dan action skill, salah satunya adalah pengamatan kolegialitas dari pelaku bimbingan konseling serta saran yang berfokus kepada kebutuhan konseli pada saat melakukan proses layanan bimbingan kelompok. Mentalitas keberanian dalam menjadi guru model pada layanan bimbingan kelompok merupakan awal dari progres untuk 'menanamkan' keterampilan konseling kepada Guru BK yang sangat diperlukan pada saat melakukan layanan konseling. Apabila ditinjau dari ketiga aspek keterampilan konseling yakni mind skill, comunication skill dan action skill, maka terdapat aspek yang perlu dilatih kembali yakni keterampilan

DipublikasikanOleh :

UPT PublikasidanPengelolaanJurnal

Universitas Islam Kalimantan Muhammad Arsyad Al-Banjari Banjarmasin 
Ratih Christiana ${ }^{1}$, Gatot Noor Effendi ${ }^{2}$, Yustina Kristiani ${ }^{3}$,

Eni Andayani ${ }^{4}$, Komisah $^{5}$, Hasma Nurhayati ${ }^{6}$

Jurnal Mahasiswa BK An-Nur :Berbeda, Bermakna, Mulia

Volume 7 Nomor 3 Tahun 2021

Tersedia Online: https://ojs.uniska-bjm.ac.id/index.php/AN-NUR p-ISSN. 2460-9722 | e-ISSN. 2622-8297

dalam bertindak atau action skill dan keterampilan berkomunikasi atau comunication skill.

Alasan yang mendasarinya adalah action skill dan comunication skill merupakan aspek psikomotor yang tampak, sehingga Guru BK membutuhkan pertimbangan untuk mengimplementasikannya karena berkaitan dengan norma dan budaya yang diamati dalam kegiatan Lesson Study for Learning Community (LSLC) pada open class (Rini, 2017) untuk meningkatkan kualitas layanan bimbingan kelompok dengan keterampilan konseling. Sedangkan mind skill adalah unsur kognitif yang intern, sehingga Guru BK di SMK tempat penelitian lebih leluasa untuk mengimplementasikannya dengan berpikir, berkreasi dan berfantasi pada proses layanan bimbingan kelompok. Selanjutnya, penelitian yang bertujuan untuk meningkatkan keterampilan konseling Guru BK di SMK dengan penerapan open class dalam layanan bimbingan kelompok sebagai sarana, tentunya membutuhkan masukan dari ilmuwan lain dan para peneliti bidang bimbingan dan konseling yang memperdalam tentang kajian serupa.

\section{Ucapan Terima Kasih}

Penelitian ini didukung oleh Direktorat Sumber Daya Dikti, Universitas PGRI Madiun dan SMK Negeri 5 Madiun.

\section{REFERENSI}

Ahmad, Fadloli. 2019. "Tata Tertib Open Class Dalam Lesson Study." Retrieved (https://gusndol.com/2019/09/01/tata-tertibopen-class-dalam-lesson-study/).

Burck, Andrew M., Laura Bruneau, Lisa Baker, and Lori Ellison. 2014. "Emerging Counselors' Perception of Wellness." Counseling Outcome Research and Evaluation 5(1):39-51.

Christiana, R \& Krisphianti, Y. .. 2020. "Analisis Rasch Pada Skala Efikasi Diri Akademik Praktikuk Konseling." Jurnal Kependidikan: Jurnal Hasil Penelitian Dan Kajian Kepustakaan Di Bidang Pendidikan, Pengajaran Dan Pembelajaran 6(1):111-18.

Dudley, P. 2015. Lesson Study Professional Learning For Out Time.

Flecknoe, Mervyn. 1999. "Collegiate Ineffectiveness: A Need for Assertive Subject Leaders." Management in Education 13(5):17-20.

Gask, L \& Graham, C. 2014. A B C Of Anxiety and
Depression. BMJ Books is an imprint of BMJ Publishing Group Limited.

Jones, R. N. 2005. Practical Counseling and Helping Skills.

Jones, R. N. 2014. "Basic Counselling Skills.” P. 511 in South African Medical Journal. Vol. 104.

Mappiare-at, Andi, M. Ramli, and Carolina L. Radjah. 2020. "Spectrum of Guidance and Counseling Services Implementation in Strengthening Character in Junior High School." 501(Icet):186-92.

Menendez, Joanna, Marisa Franco, Jaleh Davari, Philip B. Gnilka, and Jeffrey S. Ashby. 2020. "Barriers and Facilitators to Latinx College Students Seeking Counseling." Journal of College Student Psychotherapy 34(4):302-15.

Mullen, Patrick R., Olivia Uwamahoro, Ashley J. Blount, and Glenn W. Lambie. 2015. "Development of Counseling Students' SelfEfficacy During Preparation and Training." The Professional Counselor 5(1):175-84.

Nita, Rahma Wira, Eva Kartika Wulan Sari, and Citra Imelda Usman. 2020. "Inovasi Pelayanan Konseling Dalam Kerangka Merdeka Belajar." Prosiding Seminar Nasional Bimbingan Dan Konseling Universitas Negeri Malang 80-88.

Rini, Ambar Prisetia. 2017. "Lesson Study for Learning Community (LSLC).” 25-38.

Saito, Eisuke, and Masaaki Sato. 2012. "Lesson Study as an Instrument for School Reform: A Case of Japanese Practices." Management in Education 26(4):181-86.

Suharni \& Christiana, R. 2020. Profesionalisasi Bimbingan Dan Konseling. Madiun: UNIPMA Press.

Suryadi, Bambang, Dian Ratna Sawitri, Bahrul Hayat, and M. Dwirifqi Kharisma Putra. 2020. "The Influence of Adolescent-Parent Career Congruence and Counselor Roles in Vocational Guidance on the Career Orientation of Students." International Journal of Instruction 13(2):45-60.

Susilo, Herawati. 2013. "Lesson Study Sebagai Sarana Meningkatkan Kompetensi Pendidik." Seminar Dan Lokakarya PLEASE 2013 Di Sekolah Tinggi Theologi Aletheia Jalan Argopuro 28-34 1-32.

DipublikasikanOleh :

UPT PublikasidanPengelolaanJurnal

Universitas Islam Kalimantan Muhammad Arsyad Al-Banjari Banjarmasin 